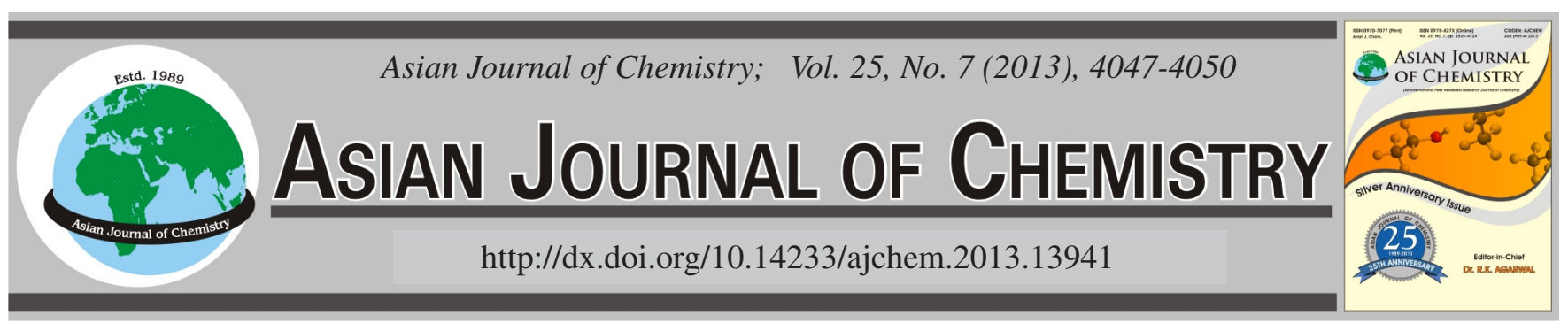

\title{
Purification Process of Daphnetin from Zushima Herb. by Macroporous Adsorbent Resin
}

\author{
Yan Liu*, Huimin Bi, Fuying You, Junping Hu, Mengmeng Shang and Hongyan Zhou
}

Handan Key Laboratory of Organic Small Molecule Materials, Handan College, Handan, Hebei, P.R. China

*Corresponding author: E-mail: liuyan7314@126.com

(Received: 23 April 2012;

Accepted: 25 January 2013)

AJC-12751

\begin{abstract}
To study the conditions and parameters for the purification of daphnetin with macroporous adsorbent resin, the adsorption and desorption of nine macroporous adsorbent resins for daphnetin were compared. The optimal adsorbent was HPD-722. The appropriate adsorption/ desorption conditions were determined. Conditions are as follows: the concentration of daphnetin in extract solution was at $0.384 \mathrm{~g} / \mathrm{L}$, $\mathrm{pH}$ value of 7 to 8 , volume at $20 \mathrm{BV}$, the extract solution passed through the column at a flow rate of $1 \mathrm{BV} / \mathrm{h}$ and room temperature, $65 \%$ alcohol was satisfactory eluant for desorption, the column was washed with $3 \mathrm{BV} 65 \%$ alcohol at a flow rate of $2 \mathrm{BV} / \mathrm{h}$. The purity of daphnetin was increased to $70 \%$ or more.
\end{abstract}

Key Words: Zushima Herb, Daphnetin, Macroporous adsorbent resin, Purification.

\section{INTRODUCTION}

Zushima Herb. is the stem and root bark of daphne tangutica Maxim. The main component are daphnin, stellera glycosides, saponins, etc. It was proved by pharmacological and clinical trials that daphnin has antiinflammatory and analgesic effects. Zushima Herb. is used in patients with rheumatoid arthritis ${ }^{1,2}$. Macroporous resin adsorption technology has been applied in research and production in the separation of the active ingredients of natural products ${ }^{3-9}$. But the research of purification process of daphnetin from Zushima Herb. by macroporous adsorbent resin is carried minimal. The adsorption and desorption of nine macroporous adsorbent resins for daphnetin were compared. The HPD-722 macroporous resin was selected as adsorbents. Aqueous ethanol solution was the eluent. The extraction and separation method was highly efficient and environmentally friendly.

\section{EXPERIMENTAL}

HPLC method was performed on a Shimadzu 2010A HPLC system. A VP ODS $C_{18}$ column $(150 \mathrm{~mm} \times 4.6 \mathrm{~mm}$, $5 \mu \mathrm{m}$ size) was used.

Zushima Herb. was purchased from Huazhong Chinese Herbal Medicine Co. Ltd., Shijiazhuang, P.R. China. Daphnin reference standard was purchased from National Institues for Food and Drug Control (batch number: 110900-200 405). Methanol were HPLC grade and purchased from Damao Chemicals Co. Ltd., Tianjin, P.R. China. Water were HPLC grade. The other chemicals and solvents used in the experiment were analytical grade. The manufacturers of macroporous resin are shown in Table-1.

Pretreatment and regeneration of macroporous adsorption resin: The new resin was soaked with $95 \%$ ethanol for $24 \mathrm{~h}$ and fully swelled. Then the resin layer was washed with $95 \%$ ethanol at a flow rate of $2 \mathrm{BV} / \mathrm{h}$ until the colour of the effluent changed from white turbidity to clear when water was added to the effluent ${ }^{10-13}$.

When regenerated, the wet macroporous resin was packed in column, eluted by $95 \%$ alcohol at $2 \mathrm{BV} / \mathrm{h}$ flow rate until did not change any longer after it was used. The resin was washed with water to no alcohol, first washed with $5 \% \mathrm{HC} 1$ for $1 \mathrm{~h}$ at $2 \mathrm{BV} / \mathrm{h}$ flow rate and washed with water to neutral, then washed with $5 \% \mathrm{NaOH}$ for $1 \mathrm{~h}$ at $2 \mathrm{BV} / \mathrm{h}$ and further washed by water until a neutral $\mathrm{pH}$ was reached ${ }^{14,15}$.

Preparation of the extract solution: Zushima Herb.were crushed. Then $100 \mathrm{~g}$ powder was put into a conical flask with stopper, soaked with $1000 \mathrm{~mL} 60 \%$ ethanol for $24 \mathrm{~h}$, under

TABLE-1

MANUFACTURER OF MACROPOROUS RESIN

\begin{tabular}{cccc}
\multicolumn{4}{c}{ MANUFACTURER OF MACROPOROUS RESIN } \\
\hline Macroporous resin models & X-5, AB-8, NKA-9, D101 & HPD-400, HPD-72 & HPD-100, DM301, DM130 \\
\hline \multirow{2}{*}{ Manufacturer } & $\begin{array}{c}\text { Guangfu Fine Chemical Research } \\
\text { Institute, Tianjin, China }\end{array}$ & $\begin{array}{c}\text { Boen adsorption Materials Technology } \\
\text { Co. Ltd., Cangzhou, China }\end{array}$ & $\begin{array}{c}\text { Haiguang Chemical Co. Ltd., } \\
\text { Tianjin, China }\end{array}$ \\
\hline
\end{tabular}


ultrasonic extraction at $30{ }^{\circ} \mathrm{C}$ for $2.5 \mathrm{~h}$, then filtered. The filtrate was concentrated to $c a .400 \mathrm{~mL}$ ethanol under vacuum, placed on the refrigerator overnight, centrifuged. The supernatant was removed, refluxed for $1 \mathrm{~h}$ with $6 \mathrm{~mL} 6 \mathrm{~mol} / \mathrm{L} \mathrm{HCl}$, then added $\mathrm{NaOH}$ to adjust $\mathrm{pH}$ to 7-8 and filtered. Finally, the extract solution was obtained and appropriate dilution when using.

Establishment of HPLC method: Chromatographic column: VP ODS $\mathrm{C}_{18}(150 \mathrm{~mm} \times 4.6 \mathrm{~mm}, 5 \mu \mathrm{m})$; volume flow: $1.0 \mathrm{~mL} \mathrm{~min}^{-1}$; column temperature: $30^{\circ} \mathrm{C}, 324 \mathrm{~nm}$ of detection wavelength; injection volume: $10 \mu \mathrm{L}$; mobile phase: methanol- $0.5 \%$ acetic acid solution (30:70). Validation of the method was done.

$9.5 \mathrm{mg}$ daphnin was weighed precisely, then put into $50 \mathrm{~mL}$ volumetric flask, plus a small amount of methanol to dissolve the daphnin and set constant volume by adding water, finally made as reference solution with $0.19 \mathrm{mg} \mathrm{mL}^{-1}$.

$1,2,3,5,8$ and $10 \mathrm{~mL}$ reference solution was draw precisely, then put into $10 \mathrm{~mL}$ volumetric flasks and set constant volume by adding water. Under the above chromatographic conditions and methods, the test samples were analyzed. Results indicated that the peak area and concentration of daphnin was a good linear relationship within the range of $0.019-0.19 \mathrm{~g} / \mathrm{L}$.

Static adsorption and desorption: $25 \mathrm{~mL}$ extract solution diluted 10-fold was loaded into a conical flask containing $1 \mathrm{~g}$ pretreated macroporous resin and then shaken at $30{ }^{\circ} \mathrm{C}$ for $6 \mathrm{~h}$ until adsorption equilibrium was reached. To calculate the adsorption capacity, the daphnin concentration in the test solution was determined by HPLC method. The desorption experiments were carried out as follows: $25 \mathrm{~mL}$ $60 \%$ ethanol solution was added to the drained resin and then shaken at $30{ }^{\circ} \mathrm{C}$ for $12 \mathrm{~h}$ until desorption equilibrium was achieved. By detection and calculation, the desorption rate can be obtained. The best adsorbent was selected in terms of its high adsorption and desorption capacity.

Dynamic adsorption and desorption: $10.0 \mathrm{~g}$ the selected macroporous resin was packed in column $(\Phi 2 \times 30 \mathrm{~cm}$, ca. $18 \mathrm{~mL}$ ), the extract solution washed through it at a certain velocity. The daphnin concentration in the effluent solution was determined by HPLC method. The effect of the flow rate and the concentration of the extact solution and other factors on the macroporous resin adsorption performance was investigated. The resin after desorption equilibrium was eluted by alcohol solution. The effect of the amount and the flow rate of the eluent on the macroporous resin adsorption performance was investigated. By dynamic adsorption and desorption experiment, the best adsorption conditions were identified.

\section{RESULTS AND DISCUSSION}

Selection of the macroporous resin: The static adsorption properties of 9 types of resin from three manufacturers were studied at $30^{\circ} \mathrm{C} .60 \%$ ethanol was used in the desorption experiments. Results are shown in Table-2. Considering the balance between adsorption and desorption rate, the HPD-722 resin was selected to seperate daphnetin from Zushima Herb.

Choice of $\mathbf{p H}$ value of the extract solution: The $\mathrm{pH}$ value of the extract solution was adjusted to 5, 6, 7, 8, 9. HPD-722 resin was used in the static adsorption experiments at $30^{\circ} \mathrm{C}$. The results are shown in Table-3. Data showed that the adsorption rate increased with increasing $\mathrm{pH}$ value. But daphnetin is acidic and may react with $\mathrm{NaOH}$ in alkaline conditions. By UV scanning, a significant change in the maximum absorption peak was confirmed. Therefore, the $\mathrm{pH}$ value was selected as 7 to 8 .

\begin{tabular}{cccccc}
\multicolumn{6}{c}{ TABLE-3 } \\
EFFECT OF PH ON THE ADSORPTION \\
PERFORMANCE OF THE HPD-722 RESIN \\
\hline $\mathrm{pH}$ & 5 & 6 & 7 & 8 & 9 \\
\hline Adsorption rate $(\%)$ & 66.29 & 69.20 & 78.70 & 82.94 & 88.25 \\
\hline
\end{tabular}

\section{Static adsorption properties of resin}

Adsorption isotherm: The adsorption isotherm of HPD722 resin at $30^{\circ} \mathrm{C}$ was shown in Fig. 1. It can be seen from the figure that the adsorption rate of resin decreased rapidly at $2 \mathrm{~h}$ and the static adsorption to saturation at the same time. The adsorption isotherm was tested in 25,30 and $40{ }^{\circ} \mathrm{C}$ separately. The adsorption rate was $80.67,77.9$ and $76.22 \%$. The results showed that the adsorption rate decreased with increasing temperature and the macroporous resin adsorption effect is the best at $25{ }^{\circ} \mathrm{C}$. Therefore, the adsorption process was exothermic and the dynamic adsorption test can be performed at room temperature.

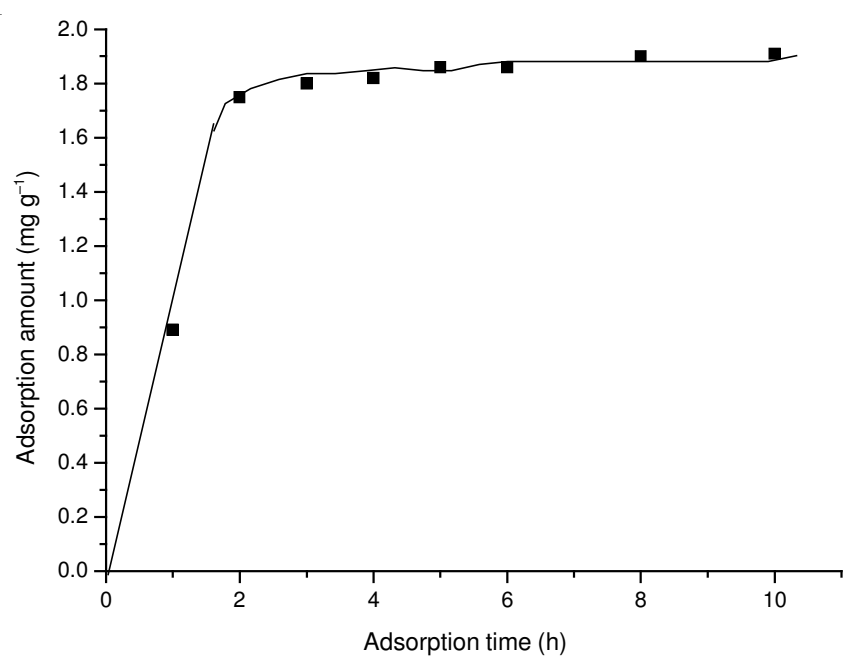

Fig. 1. Adsorption isotherm of HPD-722 resin at $30^{\circ} \mathrm{C}$

Choice of the eluant: The concentration of ethanol solution have a greater impact on the desorption rate of the macroporous resin. When the ethanol concentration was $45 \%$,

TABLE-2

STATIC ADSORPTION AND DESORPTION DATA OF 9 TYPES OF RESIN

\begin{tabular}{lcccccccccc}
\multicolumn{1}{c}{ STATIC ADSORPTION AND DESORPTION DATA OF 9 TYPES OF RESIN } \\
\hline \multicolumn{1}{c}{ Type } & X-5 & AB-8 & NKA-9 & D101 & HPD-400 & HPD-722 & HPD-100 & DM301 & DM130 \\
\hline Adsorption capacity $\left(\mathrm{mg} \mathrm{g}^{-1}\right)$ & 0.85 & 1.37 & 1.21 & 0.88 & 1.32 & 1.75 & 0.74 & 0.41 & 1.19 \\
Desorption rate (\%) & 96.3 & 92.4 & 91.8 & 95.6 & 89.7 & 94.2 & 93.1 & 92.8 & 95.8 \\
\hline
\end{tabular}


the desorption rate was only $73.29 \%$. When the ethanol concentration increased to $65 \%$, the desorption rate was $98.68 \%$. But if the ethanol concentration continued to increase, the desorption rate would decrease. Therefore, $65 \%$ ethanol was selected as the desorption eluent.

\section{Dynamic adsorption properties of resin}

Dynamic adsorption curves: $10 \mathrm{~g}$ of the wet HPD-722 resin was packed in column. $0.126 \mathrm{~g} / \mathrm{L}$ extract solution washed through it in $2 \mathrm{BV} / \mathrm{h}$ flow rate. Effluent solution was collected every $1 \mathrm{BV}$ copy. The daphnin concentration in the effluent was determined by HPLC method and the dynamic adsorption curves was shown in Fig. 2. With the sample volume increasing, the daphnin concentration increased gradually in the effluent. Corresponding in concentration in the effluent solution of $5 \%$ of the extract concentration, the resin can be handled $20 \mathrm{BV}$ on the extract solution and the saturated adsorption capacity of the resin is $4.54 \mathrm{mg} / \mathrm{g}$. When the effluent reached $26 \mathrm{BV}$, the daphnin concentration in the effluent and the extract was the same.

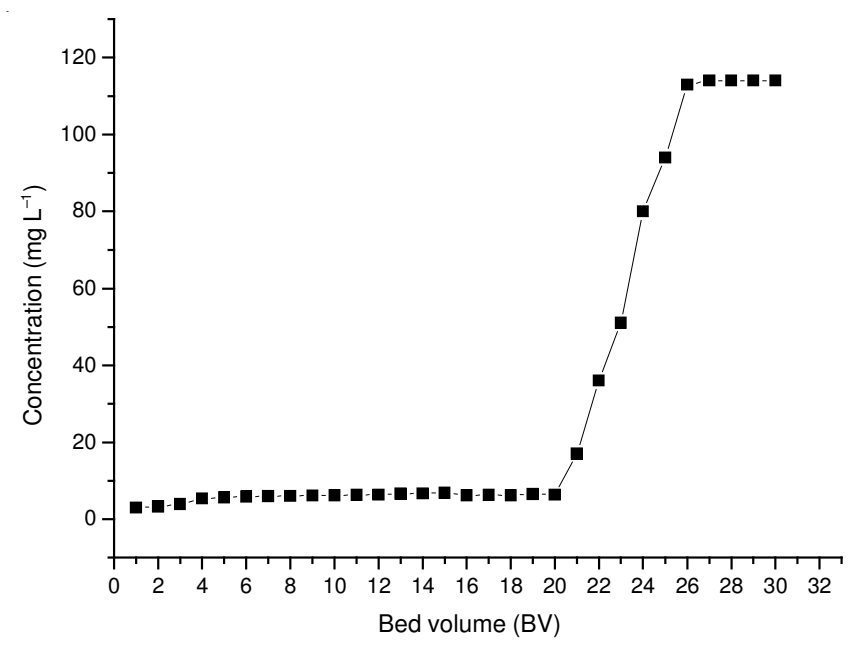

Fig. 2. Dynamic adsorption curve of HPD-722 resin

Effect of the sample flow rate on the adsorption: 1, 2 and $3 \mathrm{BV} / \mathrm{h}$ flow rate on dynamic adsorption of HPD-722 resin was investigated separately. The results show that the flow rate has little effect on sample volume, but the saturated adsorption capacity increased with decreasing flow rate. When the flow rate was $1 \mathrm{BV} / \mathrm{h}$, the saturation adsorption capacity can be up to $4.93 \mathrm{mg} / \mathrm{g}$. Taking into account the time factor, it was determined that the optimum flow rate was $1 \mathrm{BV} / \mathrm{h}$ and the extract solution volume was $20 \mathrm{BV}$.

Effect of the sample concentration on the adsorption: The effect of the sample concentration on the saturation adsorption capacity of HPD-722 resin was investigated. The sample concentration was $0.768,0.384,0.154$ and $0.077 \mathrm{~g} / \mathrm{L}$. The flow rate was the same. Data was shown in Table-4. The results showed that the adsorption capacity of the resin increased with increasing the sample concentration. But when the concentration was greater than $0.384 \mathrm{~g} \mathrm{~L}^{-1}$, the adsorption rate was worse because multilayer adsorption would cause the resin porous blockage. Therefore,optimum concentration of the sample was selected as $0.384 \mathrm{~g} \mathrm{~L}^{-1}$.

\begin{tabular}{|c|c|c|c|c|}
\hline $\begin{array}{r}\text { TA } \\
\text { EFFECT OF } \\
\text { CONCENTRATION }\end{array}$ & $\begin{array}{l}\text { E-4 } \\
\text { HE SAM } \\
\text { THE A }\end{array}$ & $\begin{array}{l}\text { LEE } \\
\text { SORP }\end{array}$ & & \\
\hline Sample concentration $\left(\mathrm{g} \mathrm{L}^{-1}\right)$ & 0.768 & 0.384 & 0.154 & 0.077 \\
\hline $\begin{array}{l}\text { Saturation adsorption capacity of } \\
\text { HPD722 resin }\left(\mathrm{mg} \mathrm{g}^{-1}\right)\end{array}$ & 4.81 & 5.22 & 4.93 & 4.65 \\
\hline
\end{tabular}

Determination of the elution rate: When the adsorption capacity of HPD-722 resin reached saturation, first the resin column was eluted with water to wash away the water-soluble substances and then eluted with $65 \%$ ethanol solution at a flow rate of 1, 2 and $3 \mathrm{BV} / \mathrm{h}$. Collection of one part per 0.5 $\mathrm{BV}$ and the daphnin concentration in the effluent was determined. The results showed that the desorption rate increased with decreasing the flow rate of eluent. However, as shown in Fig. 3, when the flow rate of $2 \mathrm{BV} / \mathrm{h}$, the desorption was concentrated and the content of daphnin is high, desorption rate was $90 \%$ or more and elution efficiency was the best. Therefore, it was determined that the elution flow rate was $2 \mathrm{BV} / \mathrm{h}$ and the eluent volume was $3 \mathrm{BV}$.

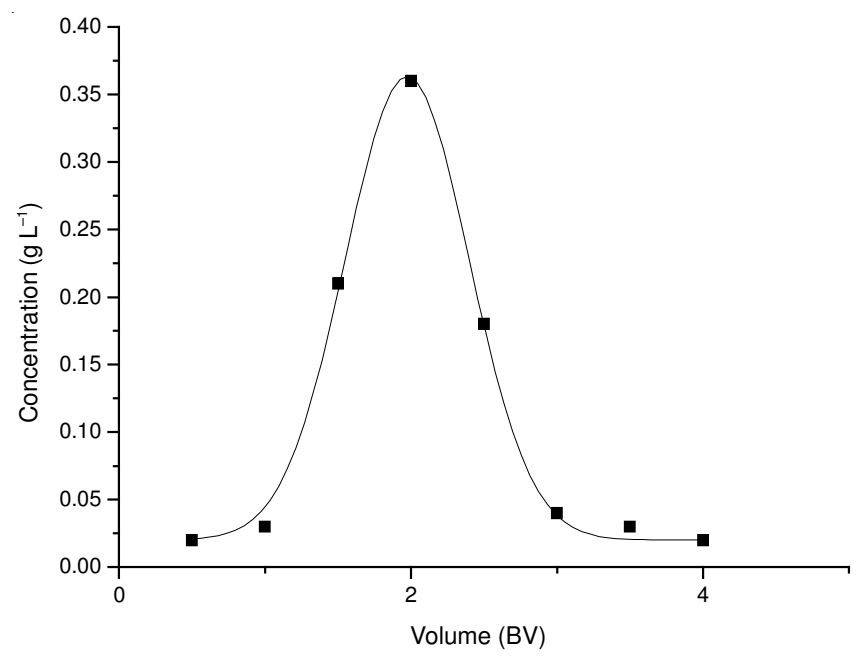

Fig. 3. Dynamic desorption curve of HPD-722 resin

\section{Conclusion}

HPD-722 macroporous resin has good results for daphnetin adsorption and elution process. The appropriate adsorption/desorption conditions were determined. Conditions are as follows: the concentration of daphnetin in extract solution was at $0.384 \mathrm{~g} / \mathrm{L}, \mathrm{pH}$ value of 7 to 8 , volume at 20 $\mathrm{BV}$, the extract solution passed through the column at a flow rate of $1 \mathrm{BV} / \mathrm{h}$ and room temperature, $65 \%$ alcohol was satisfactory eluant for desorption, the column was washed with $3 \mathrm{BV} 65 \%$ alcohol at a flow rate of $2 \mathrm{BV} / \mathrm{h}$. According the above conditions, the HPLC chromatograms of Zushima Herb. after HPD-722 resin purification was shown in Fig. 4. It can be seen that the main impurities had been a lot of removal by macroporous resin and the purity was increased to more than $70 \%$. The method of extraction and elution used ethanol solution and regenerated resin can be used repeatedly. Therefore, the method is environmentally friendly purification process and the purification process of daphnetin using HPD722 resin is feasible. 


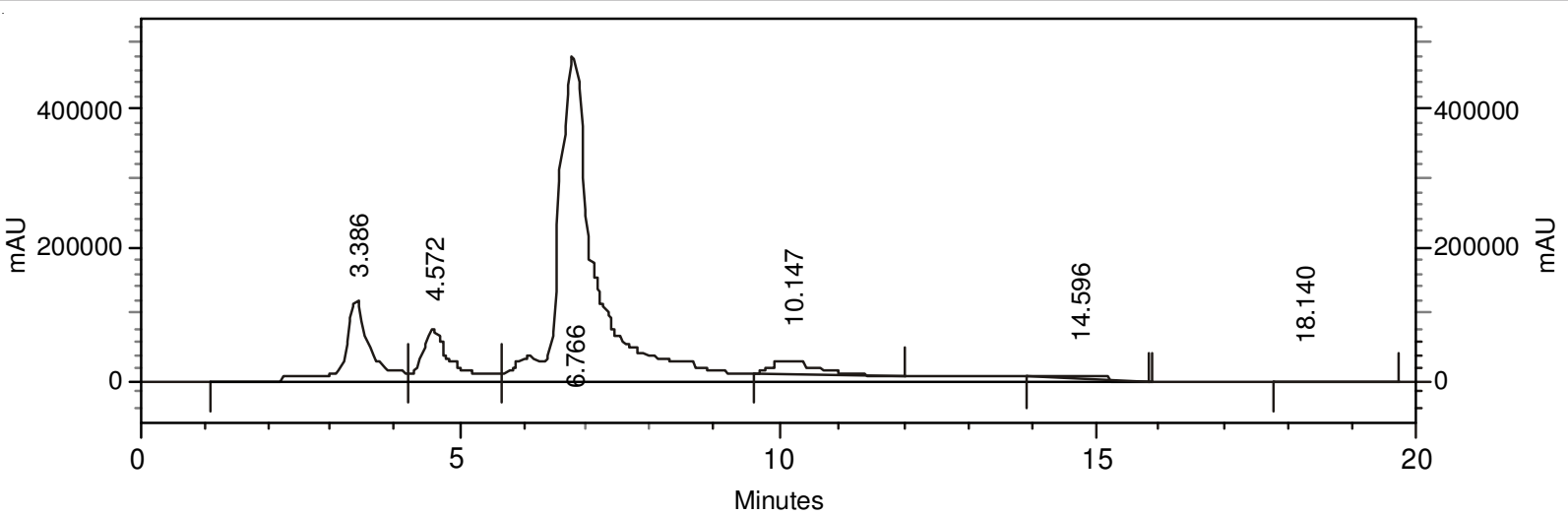

Fig. 4. HPLC chromatograms of Zushima Herb. after HPD-722 resin purification

\section{ACKNOWLEDGEMENTS}

This project was supported by the Science and Technology Projects of Hebei Province (Contract No. 10273939).

\section{REFERENCES}

1. M. Deiana, A. Rosa, V. Casu, F. Cottiglia, L. Bonsignore and M.A. Dessi, J. Am. Oil Chem. Soc., 80, 65 (2003).

2. D.A. Egan, C. Duff, L. Jordan, R. Fitzgerald, S. Connolly and G. Finn, Chromatographia, 58, 649 (2003).

3. D.L. Hua, C.Q. Ma, L.F. Song, S. Lin, Z.B. Zhang, Z.X. Deng and P. Xu, Appl. Microbiol. Biotechnol., 74, 783 (2007).

4. L.Y. Yao, L.W. Wang, B. Zhao, X.F. Yuan, X.D. Wang, Y.C. Wang, H.M. Su and S.M. Niu, Asian J. Chem., 24, 871 (2012).

5. Y. Wang, Z.X. Lu, X.M. Bie and F.X. Lv, Eur. Food Res. Technol., 231, $189(2010)$
6. R.F. Wang, J.L. Yang and Z.Q. Shi, Frontiers Chem. Eng. China, 2, 171 (2008).

7. Q. Huo and X.M. Gu, Asian J. Chem., 22, 6891 (2010).

8. M. Jie, C.P. Wan, Y.Y. Yu and S.W. Cao, Asian J. Chem., 23, 3964 (2011).

9. Y.F. Liu, L. Shan and X.G. Wang, J. Am. Oil Chem. Soc., 86, 183 (2009).

10. Z.P. Yin, B.Y. Zhang and H.Y. Chen, Frontiers Agric. China, 5, 637 (2011).

11. V. Tharanitharan and K. Srinivasan, Asian J. Chem., 22, 3036 (2010).

12. L.A. Rodrigues and M.L.C.P. da Silva, Adsorption, 16, 173 (2010).

13. S. Haider, Z.X. Li and H. Lin, J. Ocean Univ. China (Eng. Ed.), 8, 425 (2009).

14. B.Q. Fu, J. Liu, H. Li, L. Li and F.S.C. Lee and X.R. Wang, J. Chromatogr. A, 1089, 18 (2005).

15. E.M. Silva, D.R. Pompeu and Y. Larondelle, Sep. Purif. Technol., 53, 274 (2007) 